\title{
The importance of inhalation volume when measuring smoking behavior
}

\author{
RONALD I. HERNING, JOHANNA S. HUNT, and REESE T. JONES \\ Langley Porter Psychiatric Institute, University of California, San Francisco, California
}

\begin{abstract}
Theoretical and technical considerations of measuring puff and inhalation volumes during cigarette smoking are reviewed. Measures of smoking behavior using a flowmeter and inductance plethysmography are described and demonstrated with seven subjects smoking over a 3to 4-h period. Puff volume and duration, inhaled volume and duration, interpuff and intercigarette interval, and number of puffs varied for each individual over the session. The ratio of puff volume to inhaled volume changed with successive cigarettes. Smokers adjust the concentration of smoke by blending air with the smoke. Thus, to completely characterize smoking behavior, the volume of smoke and air inhaled into the lungs must be measured directly.
\end{abstract}

Tobacco smokers have many options for varying exposure to nicotine, tar, and other combustion products in cigarette smoke. Frequency of smoking and the machine-delivered doses are obviously contributing factors. Number of puffs, interpuff interval, and puff and inhalation volume and duration can vary. A device for measuring puff volume, first described by Guillerm and Radziszewski (1975), or variations of it have been used in many smoking studies (Battig, Buzzi, \& Nil, 1982; Comer \& Creighton, 1978; Creighton \& Lewis, 1978a, 1978b; Guillerm \& Radziszewski, 1978; Herning, Jones, Bachman, \& Mines, 1981; Herning, Jones, Benowitz, \& Mines, 1983; Rawbone, Murphy, Tate, \& Kane, 1978; Sheahon, Pavia, Bateman, Agnew, \& Clark, 1981). However, puff volume measures only the amount of smoke delivered to the mouth. A few studies have measured both inhalation characteristics and puffing (Guillerm \& Radziszewski, 1978; Herning et al., 1983; Rawbone et al., 1978; Tobin \& Sackner, 1982), and these studies have provided a measure of the amount of smoke and air drawn into the lungs. Some of the most popular cigarette brands use filters that dilute smoke with air; with these, puff volume alone is a poor index of nicotine or tar dose. Relatively little attention has been given to measuring inhalation, although the theory and methodology for noninvasive measures of respiration have been available since the 1960s (Shapiro \& Cohen, 1965 ) and are used for other purposes by psychophysiologists and respiratory physiologists.

We describe methods useful in the study of selfadministration (via smoking) of any drug, for example, marijuana or cocaine. Exposure to combustion prod-

This research was supported in part by Grants DA02088, DA01696, and DA00053 from the National Institute on Drug Abuse. The authors' mailing address is: Langley Porter Psychiatric Institute, University of California, San Francisco, California 94143. ucts other than the psychoactive substance may have serious health implications. The measurement of all aspects of smoking behavior should lead to better understanding of dose regulation. Thus, the mechanisms of drug delivery and dilution during smoking are important but have generally been overlooked, perhaps because of their apparent complexity. Here we contrast our technique for measuring puff volume with other methods and describe measurement of inhalation.

The measurement of smoke exposure by biological markers in body fluids is beyond the scope of this paper. Benowitz (in press) reviewed the advantages and disadvantages of nicotine, cotinine, thiocyanate, and carbon monoxide as markers of smoke exposure. Expired carbon monoxide has often been used as an indirect measure of inhalation. Ashton, Stepney, and Thompson (1981) and Benowitz concluded that carbon monoxide may not be a good measure of smoke exposure on a single cigarette, but it can serve as an index of daily cigarette consumption. Our concern, however, is the precise measurement of puff-by-puff smoking behavior on a single cigarette.

\section{MEASURING PUFF VOLUME}

Puff volume $\left(V_{p}\right)$ is the integration over time $(t)$ of the flow (f) of the cigarette smoke into the mouth:

$$
V_{p}=\int f(d f / d t) \text {. }
$$

Flow is expressed in milliliters per second $(\mathrm{ml} / \mathrm{sec})$. Puff volume usually ranges between 0 and $100 \mathrm{ml}$. Currently, three different types of flowmeters are used to measure flow with a pressure transducer. A flowmeter (see Figure 1) is either attached to the proximal end of the cigarette or inserted between sections of the tobacco rod or between the tobacco rod and the filter. Each 


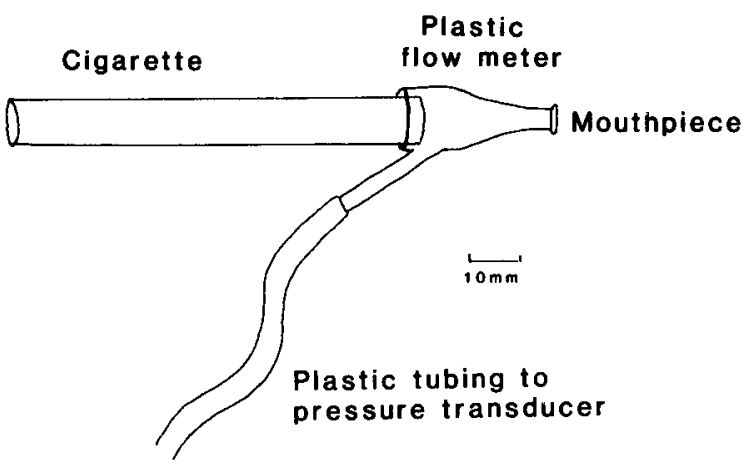

Figure 1. The flowmeter and its location on a typical kingsize cigarette. The device does not block the ventilated openings on commercially available cigarettes. It is also more natural in the sense that there is no change in draw resistance of the cigarette.

flowmeter converts flow to pressure by a slightly different principle:

$$
f_{t}=K\left(p_{t}-q_{t}\right)
$$

for laminar flow, where $f_{t}$ is flow at time $(t), p_{t}$ and $q_{t}$ are two different pressure measurements at time $(t)$, and $\mathrm{K}$ is a constant;

$$
f_{t}=K\left(p_{t}-q_{t}\right)
$$

for turbulent flow, where $f_{t}, p_{t}, q_{t}$, and $K$ represent the same parameters as in Equation 2; and

$$
f_{t}=\sum_{i=1}^{4} a_{i} p_{t} i
$$

for polynomial approximation, where $f_{t}$ and $p_{t}$ are flow and pressure at time $(t)$ and $a_{1}, a_{2}, a_{3}$, and $a_{4}$ are empirically derived constants.

Pressure is measured by a variety of commercially available transducers that are easily interfaced to any dc amplifier via a Wheatstone bridge. The pressure transducer is attached to the flowmeter by flexible plastic tubing.

The principle of converting flow to pressure is similar for the first two methods (Equations 2 and 3). Within the flowmeter, either a cellulose acetate filter (Equation 2) or restricting orifice (Equation 3) is inserted between two pressure outlets and the differential pressure across it is converted to flow by the appropriate equation. The precise determination of the constant (K) is obtained by drawing air or smoke through the transducer at known flow rates and observing the variation in differential pressure. The laminar-flow method is described by Rawbone et al. (1978), and the turbulentflow method is described by Creighton, Noble, and Whewell (1978).
Measurement errors can occur with both of these methods if there is an accumulation of combustion products during smoking on the cellulose acetate filter or on the $0.9-\mathrm{mm}$-diam restricted opening in the orifice plate. An additional problem is progressive change in flow resistance values of the burning tobacco rod (Baker, 1975). Creighton et al. (1978) measured these distortions and corrected for them electronically in their apparatus.

Gritz, Rose, and Jarvik (1983) used a flowmeter that sensed flow via a thermistor rather than via a pressure transducer. The cigarette holder contained a heated thermistor. Smoke flow through the holder reduced the temperature of the thermistor. The temperature drop was calibrated against air flow. They found a $10 \%$ error with this method when known volumes of air or smoke were drawn through the flowmeter. The accumulation of tar and nicotine in the holder did not affect the measurement of flow.

Tobin and Sackner (1982) used a single inductance coil placed vertically around the head to measure puff volume. The expansion of this coil due to cheek movement during puffing can be calibrated with a spirometer. Tobin and Sackner claimed $90 \%$ accuracy using this technique. There is some measurement error with such a technique when the smoker draws the smoke directly into the lungs. Fortunately, most tobacco smokers first draw smoke into their mouths, pause briefly, and then draw smoke and air into their lungs. Whether this technique would be useful to measure puff volume during the smoking of marijuana and cocaine, during which smokers generally inhale directly without a pause, requires further study.

Our flowmeter (Herning et al., 1981) and that used by Sheahon et al. (1981) does not add increased in-line resistance or constriction and uses only one pressure transducer. Flow is derived from pressure by the relationship in Equation 4. The flowmeter is a plastic cigarette holder (Figure 1) connected to a pressure transducer with flexible plastic tubing. The resistance of the cigarette to air or smoke flow produces negative pressure in the transducer, and the negative pressure is sensed by the single pressure transducer. The relationship between flow and this pressure is nonlinear and varies with the cigarette brand. The nonlinear relationship (Equation 4) is determined uniquely for each individual cigarette before it is smoked. Since the relationship varies between brands of cigarette as well as between cigarettes of the same brand, it is not easy to construct an analog device to convert the pressure value back to flow during the smoking of the cigarette. Thus, calibration and acquisition is done with a digital computer (Data General Eclipse S/200).

Although there is no filter or constriction in our flowmeter to accumulate combustion products, the progressive change in resistance of the burning cigarette is of consequence. When the cigarette burns, the length of 
the tobacco rod decreases, which consequently decreases the cigarette's resistance to smoke flow. However, when a cigarette is smoked, combustion products accumulate in the tobacco rod as well as in the filter. The accumulation of combustion products generates errors in the differential pressure flowmeters. The combustion products increase the resistance of the transducer used in laminar- and turbulent-flow methods. The accumulation of combustion products compensates for the decrease in tobacco-rod resistance in our flowmeter. The extent of this compensation can be empirically tested for a given cigarette type by drawing known volumes of smoke through the burning cigarette with a syringe or smoking machine. Such a test is recommended as a determination of absolute accuracy and reliability of any puff-volume measurement technique. For the University of Kentucky research cigarettes (Benner, 1970) used in our initial report (Herning et al., 1981), slight volume overestimates on the first few puffs and underestimates on the last few puffs were noted. Creighton et al. (1978) likewise estimated the inaccuracy with burning cigarettes and adjusted for it using an analog feedback loop in their apparatus.

\section{MEASURING INHALATION}

Measuring inhalation of smoke and air after a puff on a cigarette is not substantially different from measuring other aspects of respiration by noninvasive methods. The movement of the chest and abdominal cavity can be related to the volume of air (and smoke) entering or leaving the lungs. Such movements are detected by strain gauges (Shapiro \& Cohen, 1965), electrical impedance (Erlbacher, Gilbert, \& Auchincloss, 1974), magnetometers (Stagg, Goldman, \& Davis, 1978), or electrical inductance (Milledge \& Stoll, 1977). We used strain gauges in our previous work (Herning et al., 1983), but have recently switched to electrical inductance because of its relative stability over time and relative accuracy despite changing body positions (Cohen, Watson, Weisshaut, Stott, \& Sackner, 1978). However, both methods use chest and abdomen transducers, whose signals must be combined and calibrated with an accurate and reliable spirometer. Two methods of calibration have been described: isovolumic maneuver (Shapiro \& Cohen, 1965) and multiple position (Equation 5) (Watson, 1979). The procedures for using our commercially available unit (Respitrace, Ambulatory Monitoring, Inc.) recommend the multiple-position calibration procedure:

$$
\mathrm{V}_{\mathrm{T}}=\mathrm{K}_{1} \mathrm{~V}_{\mathrm{RC}}+\mathrm{K}_{2} \mathrm{~V}_{\mathrm{AD}}
$$

where $V_{T}$ is total volume, $V_{R C}$ is the volume signal from the rib-cage-transducer, and $V_{A D}$ is the volume signal from the abdomen transducer. $K_{1}$ and $K_{2}$ are derived by solving the resultant set of simultaneous equations with values for $V_{T}, V_{R C}$, and $V_{A D}$ from supine and standing positions.

Studies using direct volumetric measurement of puff and inhaled volume during smoking are summarized in Table 1.

\section{USE OF PUFFING AND INHALATION MEASURES TO STUDY SMOKING PATTERNS}

Little is known about alterations in puffing and inhalation patterns throughout the day as multiple

Table 1

Summary of Smoking Studies Using Volumetric Measures

\begin{tabular}{|c|c|c|c|}
\hline Study & Puff-Volume Method & Inhaled-Volume Method & Comments \\
\hline $\begin{array}{l}\text { Guillerm \& Radziszewski, } \\
1975,1978\end{array}$ & Laminar Flow & Impedance & $\begin{array}{l}\text { No compensation for cigarette } \\
\text { resistance employed }\end{array}$ \\
\hline Rawbone et al., 1978 & Laminar Flow & Strain Gauge & $\begin{array}{l}\text { No compensation for cigarette } \\
\text { resistance employed }\end{array}$ \\
\hline $\begin{array}{l}\text { Comer \& Creighton, } 1978 \\
\text { Creighton \& Lewis, 1978a, 1978b } \\
\text { Battig et al., } 1982\end{array}$ & Turbulent Flow & None & $\begin{array}{l}\text { Electronically compensated for } \\
\text { changes in resistance over the } \\
\text { length of the burning cigarette }\end{array}$ \\
\hline $\begin{array}{l}\text { Herning et al., } 1981 \\
\text { Sheahon et al., } 1981\end{array}$ & $\begin{array}{l}\text { Flow Approximation } \\
\text { Flow Approximation }\end{array}$ & $\begin{array}{l}\text { None } \\
\text { Radiotracer } 81 \text { n krypton }\end{array}$ & $\begin{array}{l}\text { Accuracy tested across a burning } \\
\text { cigarette }\end{array}$ \\
\hline Epstein et al., 1981 & Flow Approximation & None & No calibration \\
\hline Gust \& Pickens, 1981 & $\begin{array}{l}\text { Pneumotachygraph } \\
\text { metering air in a } \\
\text { combustion chamber }\end{array}$ & None & $\begin{array}{l}\text { Smoker must insert and } \\
\text { remove the cigarette from the } \\
\text { combustion chamber for each puff. }\end{array}$ \\
\hline Tobin \& Sackner, 1982 & $\begin{array}{l}\text { Flow Approximation } \\
\text { and Inductance }\end{array}$ & Inductance & $\begin{array}{l}\text { Inductance method does not } \\
\text { require a cigarette holder. Flow } \\
\text { approximation compared with induc- } \\
\text { tion may not be accurate with all } \\
\text { smoking patterns. }\end{array}$ \\
\hline Gritz et al., 1983 & Flow Approximation & None & $\begin{array}{l}\text { Flow approximated from temperature } \\
\text { changes }\end{array}$ \\
\hline Herning et al., 1983 & Flow Approximation & Strain Gauges & Accuracy tested with burning cigarette \\
\hline
\end{tabular}


cigarettes are smoked. Previous studies have described puff and inhalation patterns over the course of one or two cigarettes at a uniform time of day. However, these measurement techniques are useful in following smoking patterns over longer periods.

\section{METHOD}

\section{Subjects}

Five female and two male subjects were recruited through bulletin-board advertisements on this campus. The protocol was approved by the University's Committee on Human Research. The subjects were paid $\$ 5.00$ per hour. Their ages ranged from 21 to 35 years. Each usually smoked a different commercially available cigarette and is identified in the following discussions by the cigarette he or she smoked: A-Virginia Slims Light (FTC nicotine $0.6 \mathrm{mg}$, tar $7 \mathrm{mg}$ ); $\mathrm{B}-$ Benson and Hedges Light (0.7 mg, $10 \mathrm{mg})$; C-Salem Light $100 \mathrm{~s}(0.8 \mathrm{mg}, 9 \mathrm{mg})$; D-Kool Mild Menthol 100s (1.0 mg, $12 \mathrm{mg})$; E-Virginia Slims $(1.0 \mathrm{mg}$, $15 \mathrm{mg}$ ); F-Camel Regular (1.4 mg, $21 \mathrm{mg}$ ), and G-Marlboro Regular (1.0 mg, $16 \mathrm{mg}$ ).

\section{Apparatus}

A single transducer flowmeter (cigarette holder and Statham Model PM5TC pressure transducer) measured puff volume and duration. To calibrate (determine the $a_{1} s$ in Equation 4), the cigarette was placed in a flowmeter. The proximal end of the holder was attached to a manometer. The manometer was attached to a vacuum source. The manometer was specially calibrated to read and adjust flow from a vacuum source. Air was drawn through the cigarette at flow rates of $0,25,50,75$, and $100 \mathrm{ml} / \mathrm{sec}$. At each flow setting, a corresponding voltage was available from the dc amplifier (Grass Model 7P1F), and a corresponding digital value was determined by the computer. The voltage and digital values indicated the pressure corresponding to a given flow rate. The pressure value did not have to be in customary pressure units, but could be expressed in arbitrary digitizer units, since changes in scale were accounted for in coefficients $\left(a_{1} s\right)$. The $a_{1} s$ were calculated from the pairs of flow and pressure values by nonlinear least squares regression (Nash, 1979) with a fourth-order polynomial as the model. While the cigarette was smoked, the pressure values were digitized every $\mathbf{4 0} \mathrm{msec}$ from the start of each puff for $8 \mathrm{sec}$. Eight seconds was chosen to accommodate the inhalation measurement discussed below. Most puffs lasted consistently less than $8 \mathrm{sec}$. The end of puff and, consequently, the puff duration could be determined from the flow values. The pressure values were converted to flow, and flow values were numerically integrated (trapezoidal rule) for duration of the puff. The Respitrace inductance plethysmograph measured inhaled volume and duration. A Collins (Model 06031) spirometer was used to calibrate the chest and abdomen signals. Data from the flowmeter, chest, abdomen, and combined transducers were sampled every $40 \mathrm{msec}$ for $8 \mathrm{sec}$, beginning at the start of each puff. The data were stored digitally for subsequent analysis. The interpuff and cigarette intervals were measured to the nearest second.

\section{Procedure}

The subjects were asked not to smoke before arriving in the laboratory for a morning session. Calibration of the inductance device began at approximately $0800 \mathrm{~h}$, and smoking began at approximately $0830 \mathrm{~h}$. Expired-breath carbon-monoxide levels determined compliance with the nonsmoking restriction and also were measured after each cigarette. After smoking the first cigarette of the day at $0830 \mathrm{~h}$, the subjects were allowed to smoke cigarettes as they chose for a period of $4 \mathrm{~h}$. They sat quietly reading or listening to a radio.

\section{Analysis}

Smoking measures for each cigarette included number of puffs, mean interpuff interval, mean puff volume, mean puff duration, mean inhaled volume, mean inhaled duration, percentage of tobacco rod smoked, and number and temporal pattern of cigarettes smoked over the 4-h period.

\section{RESULTS}

\section{Calibration Procedure}

The air-flow calibration was plotted versus pressure for six cigarettes of each brand used in the study (Figure 2). In no case was the flow-to-pressure relationship entirely linear. The flow-to-pressure relationship differed for each brand. Occasionally, large differences were observed for cigarettes from the same package (see Figures $2 \mathrm{~A}$ and $2 \mathrm{E}$ ). To reduce between-cigarette measurement error, the air-flow calibration of each cigarette to be smoked in the experiment was mandatory.

To chart the effects of flow-resistance changes during smoking, burning-cigarette accuracy tests were also conducted on University of Kentucky research cigarettes (Benner, 1970) and on commercially available cigarettes. A glass syringe was used to draw the exact volume of smoke from the burning cigarettes. Although the volume drawn was accurate, the duration of each simulated puff varied $(1.3 \mathrm{sec})$, since the syringe was drawn to the appropriate volume manually. The computer-derived volumes were compared with the actual volumes. For the 30 research cigarettes tested, the average error expressed as a percentage of the standard [(computer volume -standard volume/standard volume) $\mathrm{x} 100 \%$ ] was $13 \%$. For the 5 commercial cigarettes of various brands, the average error over all puffs was $10 \%$. These are estimates of the measurement error per puff. The measurement error per cigarette was $8 \%$. The reduction measurement error with repeated observations was due to random over- and underestimates of the true volume across the puffs on a single cigarette.

The chest, stomach, and combined signals from the inductance plethysmograph are shown before and after calibration with the spirometer (Figure 3). Before calibration, the combined signal reflected the spirometer signal in periodicity but not in amplitude. The correction factors for the chest and stomach signals were derived from Equation 5. Once the corrections in the amplitude of the individual signals were made, the combined signal was identical to the spirometer tracing. With careful calibration, $90 \%$ accuracy was possible for all body positions (Watson, 1980). The accuracy was tested with a water spirometer as a standard. Thus, the $10 \%$ error found was calculated as a percentage of the standard [(inductance volume-spirometer volume/ spirometer volume) $\times 100 \%]$.

\section{Self-Paced Smoking}

The means of puffing and inhalation measures for each cigarette were calculated. The measures included 

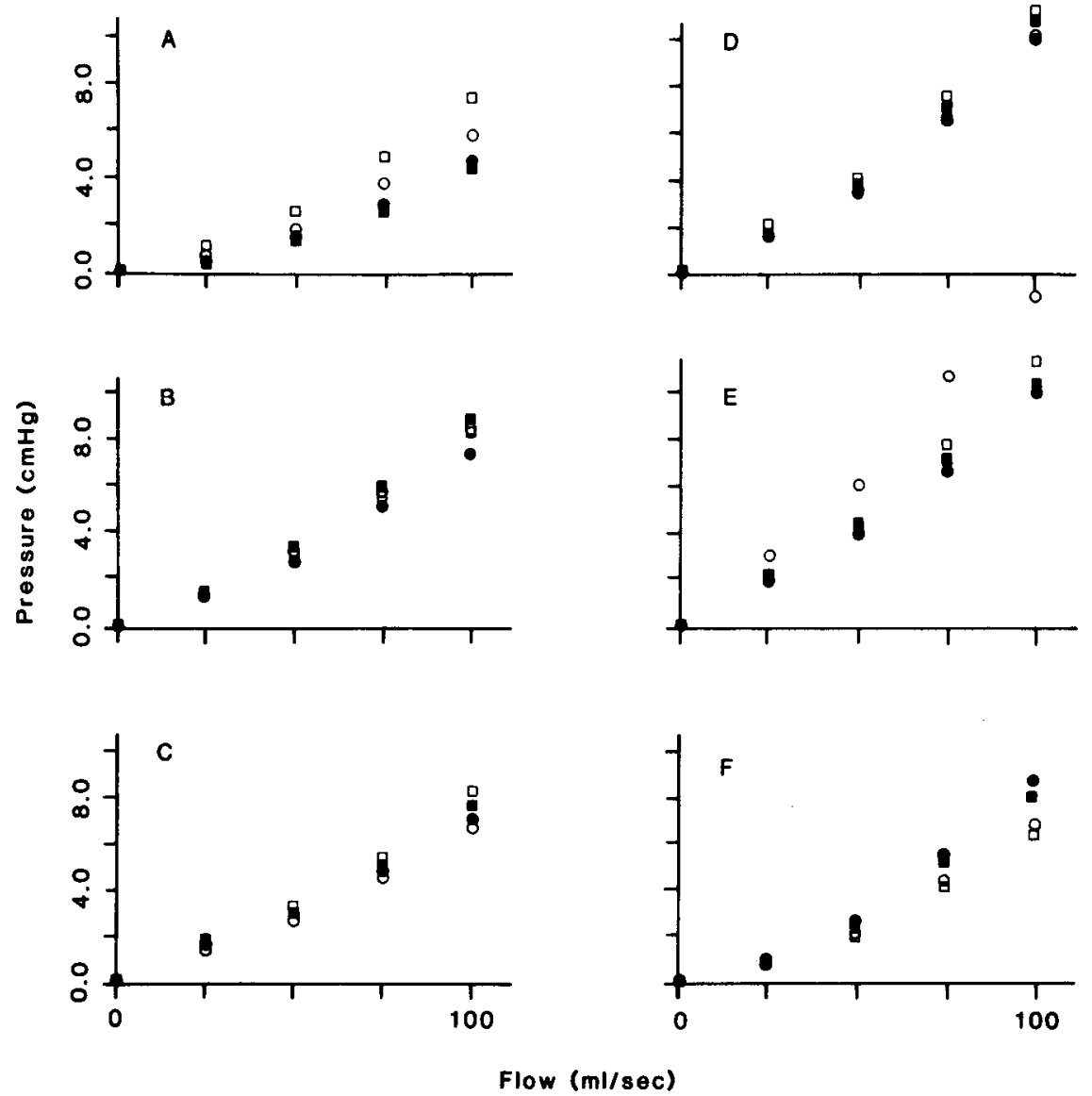

Figure 2. Pressure is plotted versus air flow for six different brands of cigarettes used in the experiment. For each brand, the data from four cigarettes, represented by four symbols, are displayed. The cigarette brands are graphed in order of increasing FTC machine yield (A-nicotine $0.6 \mathrm{mg}$, tar $7 \mathrm{gm}$; B-0.7 mg, $10 \mathrm{mg} ; \mathrm{C}-0.8 \mathrm{mg}, 9 \mathrm{mg}$; D-1.0 mg, $12 \mathrm{mg}$; E-1.0 mg, $15 \mathrm{mg}$; F$1.4 \mathrm{mg}, 21 \mathrm{mg}$ ). Cigarettes $A$ and $E$ are the lights and regulars of the same brand. The lights (A) clearly have less resistance to the air flow (lower pressures) than do the regulars (E).

Supine calibration
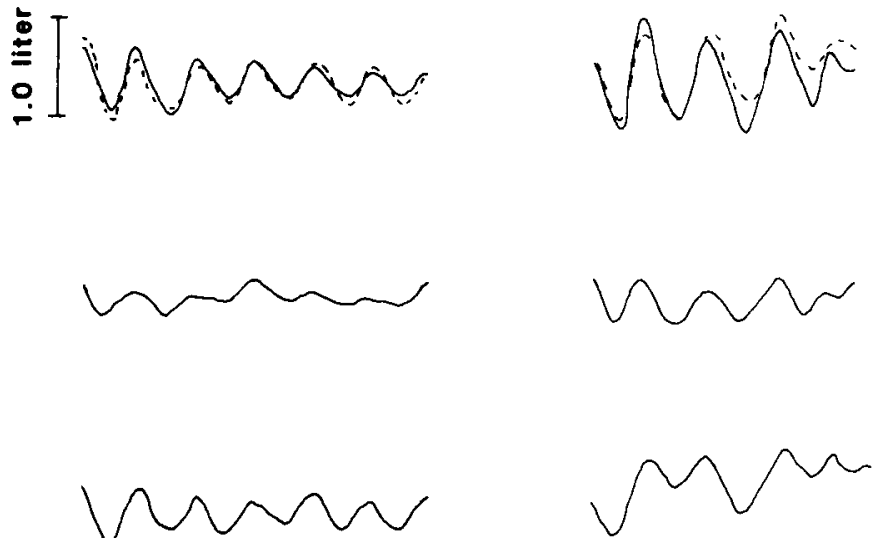

\section{Sitting after calibration}
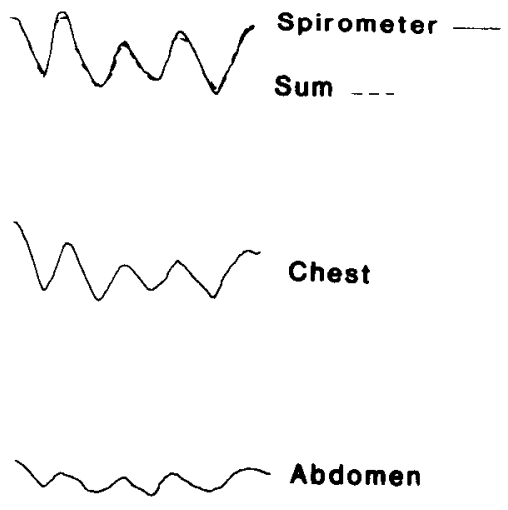

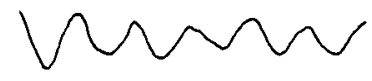

$\longmapsto$

5 sec.

Figure 3. A calibration session on the inductance plethysmograph is presented. The left column is the supine session, the center column is the standing session, and the right column is a postcalibration check. The top row is the spirometer tracing and the combined chest and abdomen signals. In the left and center columns, the combined signal is uncalibrated. In the right column, this signal is equivalent to the spirometer trace. The middle and bottom rows show the chest and abdomen tracings. These are adjusted using the values determined from supine plus standing calibration to obtain identical spirometer and combined signals. 
Table 2

Individual Subject Smoking Behavior: Means and Standard Deviations Over All Cigarettes Smoked in the 4-h Session

\begin{tabular}{|c|c|c|c|c|c|c|c|c|c|c|c|c|c|c|c|}
\hline \multirow{3}{*}{$\begin{array}{l}\text { Sub- } \\
\text { ject }\end{array}$} & \multirow{3}{*}{ Sex } & \multicolumn{14}{|c|}{ Smoking Measure } \\
\hline & & \multicolumn{2}{|c|}{$\begin{array}{c}\text { Puff } \\
\text { Volume (ml) }\end{array}$} & \multicolumn{2}{|c|}{$\begin{array}{c}\text { Puff } \\
\text { Duration (sec) }\end{array}$} & \multicolumn{2}{|c|}{$\begin{array}{c}\text { Inhaled } \\
\text { Volu, ne }(\mathrm{ml})\end{array}$} & \multicolumn{2}{|c|}{$\begin{array}{c}\text { Inhaled } \\
\text { Duration (sec) }\end{array}$} & \multicolumn{2}{|c|}{$\begin{array}{c}\text { Interpuff } \\
\text { Interval (sec) }\end{array}$} & \multicolumn{2}{|c|}{$\begin{array}{l}\text { Intercigarette } \\
\text { Interval (min) }\end{array}$} & \multicolumn{2}{|c|}{$\begin{array}{c}\text { Number of } \\
\text { Puffs }\end{array}$} \\
\hline & & Mean & SD & Mean & SD & Mean & SD & Mean & $\mathrm{SD}$ & Mean & SD & Mean & SD & Mean & SD \\
\hline $\mathbf{A}$ & $\mathrm{F}$ & 34.2 & 7.6 & 1.27 & 0.07 & 850 & 50 & 3.8 & 0.4 & 31.9 & 5.2 & 60.1 & 19.9 & 12.8 & 5.1 \\
\hline B & $\mathrm{F}$ & 31.5 & 3.4 & 2.16 & 0.17 & 860 & 130 & 2.7 & 0.4 & 33.0 & 24.2 & 37.8 & 16.0 & 12.4 & 3.3 \\
\hline $\mathrm{C}$ & $\mathbf{M}$ & 46.3 & 6.9 & 1.71 & 0.17 & 1160 & 220 & 3.5 & 0.5 & 41.6 & 8.1 & 34.8 & 6.8 & 10.6 & 1.2 \\
\hline D & $\mathrm{F}$ & 42.7 & 7.1 & 2.80 & 0.27 & 680 & 140 & 4.6 & 0.2 & 46.3 & 14.3 & 53.5 & 12.2 & 9.6 & 1.1 \\
\hline $\mathbf{E}$ & $\mathbf{M}$ & 33.3 & 4.6 & 1.37 & 0.27 & 810 & 170 & 4.9 & 0.5 & 67.2 & 39.7 & 33.2 & 5.5 & 10.5 & 3.0 \\
\hline $\mathbf{F}$ & $\mathrm{F}$ & 57.4 & 14.9 & 2.42 & 0.35 & 1170 & 260 & 6.6 & 0.7 & 63.7 & 20.0 & 44.2 & 7.5 & 8.3 & 1.4 \\
\hline $\mathrm{G}$ & $\mathrm{F}$ & 37.7 & 6.2 & 2.18 & 0.17 & 750 & 60 & 4.6 & 0.3 & 36.8 & 13.3 & 38.4 & 13.3 & 12.3 & 1.9 \\
\hline
\end{tabular}

Note $-S D=$ standard deviations; $F=$ female $; M=$ male.
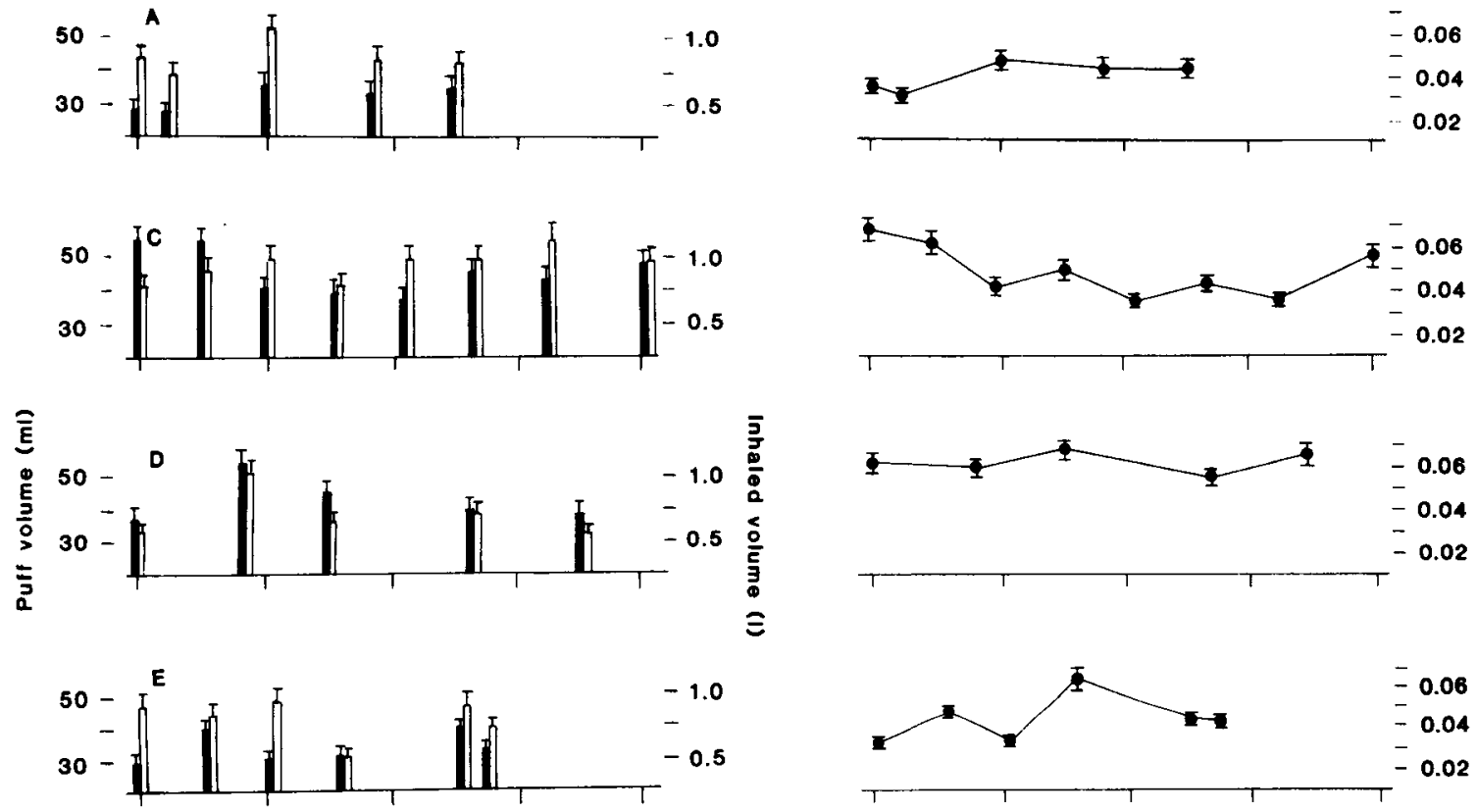

$-0.06$

$-0.04$

$-0.02$
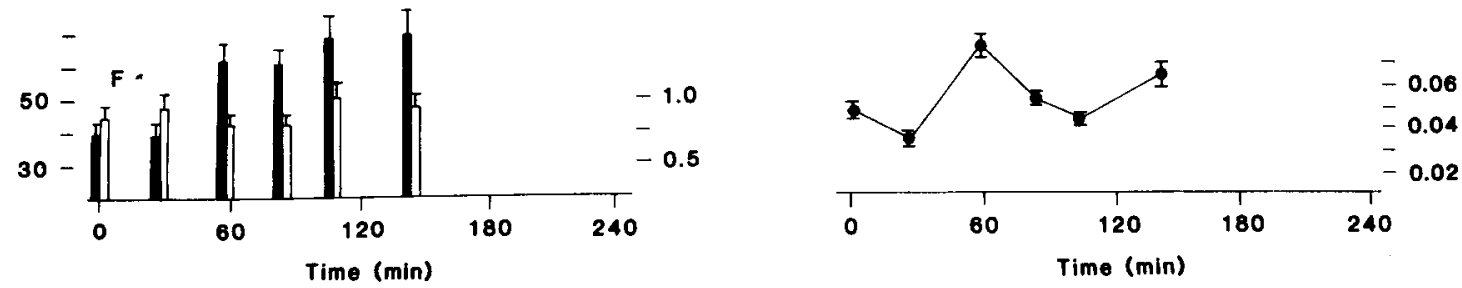

Figure 4. In the left column, puff and inhaled volumes for five subjects are presented over the course of the ad-lib smoking session. Each bar is the mean volume over all puffs on a cigarette. The dark bar is puff volume, and the light is inhaled volume. Time relative to start of smoking is on the abscissa. The ratios of smoke-to-air volume are plotted in the right column. The abscissa is similar to the left column. The scale for puff volume is on the left, for inhaled volume in the center, and for the ratios on the right. The bar on the left plot represents the $8 \%$-per-cigarette measurement error for puff volume and the $10 \%$ measurement error for inhalation volume. Since the measurement errors for puff volume and inhalation volume are independent, the error of the ratio is not a linear combination of the individual errors. The error bar for the ratios is calculated by fitting a normal distribution to range of possible errors. The bar on the right plot represents one standard deviation from that distribution.

puff volume, duration and number of puffs, interpuff interval, and inhaled volume and duration. The mean and standard deviation of these values over all cigarettes smoked by each subject are listed in Table 2 . Consider- able variability existed in each subject's smoking pattern, as well as between patterns of different subjects. The variability was not limited to a single parameter. All measures were affected. 
Of particular interest were the volumetric measures. Puff and inhaled volumes were plotted for each subject over the course of the self-paced smoking session (Figure 4). Not only were puff and inhaled volumes variable over time for each subject, but the ratio of the two measures also varied. Such a finding implied that the effective concentration of smoke delivered to the lungs was not uniform for each cigarette that these subjects smoked. This supports the notion that smokers control the dose of nicotine that they receive by blending air with the smoke as they inhale.

Puff and inhalation volumes were not the only smoking measures that varied over the four smoking sessions. Intracigarette and intersubject variability were considerable for all measures. Puff duration, inhaled duration, interpuff interval, and intercigarette interval had no measurement errors. Thus, the variability shown on these measures represents actual differences in smoking by these subjects. All measures in Table 2 influenced the amount of nicotine and combustion products a subject received while smoking.

\section{DISCUSSION}

The data from the subject-paced smoking sessions were mainly intended to illustrate the use of puff and inhalation measures. Smoking patterns were variable between cigarettes as well as between subjects. Our smokers began smoking after a 10-12-h (overnight) abstinence. Thus, the variability may have been due to the fact that the smokers were tested over a period of probably rapidly changing nicotine requirements. The results are not limited by the constraints of an imposed experimental design and suggest considerable variability in smoking patterns, at least over the course of a morning.

The relative importance of measuring inhalation volume in addition to puff volume is clearly apparent in our data. Not only did smokers vary puff and inhalation volumes as they smoked successive cigarettes throughout the morning, but also the ratio between these volumetric measures was not constant. Thus, the concentration of smoke reaching the lungs varied over cigarettes for a given subject. Such a finding is important for two reasons. First, it illustrates that smokers blend air with smoke to achieve their optimal dose. Nicotine absorption in the lungs depends on the concentration of nicotine in the smoke (Schievelbein, 1982). Second, puff volume alone is not an adequate measure of inhalation. Both must be measured.

Another method used to study smoking patterns over the day (Henningfield \& Griffiths, 1979) measured expired-breath carbon-monoxide levels as well as interpuff and intercigarette intervals. No direct measurement of puff volume or inhalation was made. Other techniques for measuring puff volume have been proposed (Gritz et al., 1983; Gust \& Pickens, 1982; Herning et al., 1981; Sheahon et al., 1981; Tobin \& Sackner, 1982) since the original European work in this area (Creighton \& Lewis, 1978a, 1978b; Creighton et al., 1978; Guillerm \& Radziszewski, 1975, 1978; Rawbone et al., 1978). Each technique has its minor advantages and disad. vantages (Table 1). All but one use a cigarette-holder flow device. This in itself may be considered a disad vantage, since smokers normally do not use such a device while smoking. The inductance method proposed by Tobin and Sackner (1982) is the only one that does not use a flowmeter. It is accurate, however, only when subjects smoke the cigarette as they draw air from a spirometer. Since it requires cheek displacement and all smokers may not bring smoke into their mouths and hold it there by expanding their cheeks, the method may not be accurate with all subjects or smoked drugs other than tobacco. The method developed by Gust and Pickens (1982) requires an extra manipulation by the subject while smoking. The subject must insert the cigarette into a combustion chamber while puffing. Such a manipulation may disrupt natural smoking more than does using a cigarette holder. Whichever method is used, careful calibration and determination of accuracy with a buming cigarette is recommended.

The measurement of inhalation volume during smoking is less common (Guillerm \& Radziszewski, 1975, 1978; Herning et al., 1981, 1983; Rawbone et al., 1978; Tobin \& Sackner, 1982). Herning et al. (1983) indicated the importance of directly measuring inhalation in tobacco smoking studies. Smokers deliver a dose of nicotine on each puff by blending the appropriate amount of air with the smoke they inhale. Various methods exist for measuring inhalation volume; Watson (1979) reviewed the relative merits of each. We have used both the strain gauge and inductance plethysmography in the measurement of inhalation. The strain gauges require more repeated calibrations to maintain accuracy, but for the measurement of inhalation on a single cigarette, they are suitable and much less expensive than is inductance plethysmography.

Smoke loss from the mouth is difficult to measure noninvasively and has not been measured by researchers. A careful observation of puffing and inhalation patterns in smokers who routinely lose part of the puff before inhaling may characterize the maneuvers that produce this loss.

No longer can tobacco researchers claim they have measured smoking behavior in the laboratory if they have only been counting the number or volume of puffs on a cigarette or measuring the interpuff interval. Numerous studies since 1975 have demonstrated the utility of measuring puff and inhalation volume and the fact that smokers use these mechanisms to adjust the delivered dose of nicotine and other drugs in the smoke.

\section{REFERENCES}

Ashton, H., Ste pney, R., \& Thompson, J. W. Should intake of carbon monoxide be used as a guide to the intake of other smoke constituents? British Medical Journal, 1981, 282, 10-13. 
BAKER, R. R. Contribution to draw resistance of a burning cigarette. Beetrage zur Tabakforschung, 1975, 8, 124-131.

BatTio, K., Buzzi, R., \& NiL, R. Smoke yield of cigarettes and puffing behavior in men and women. Psychopharmacology, 1982, 76, 139-148.

BEnNeR, J. F. Tentative summary of leaf and smoke analysis of the University of Kentucky reference and alkaloid cigarettes. In R. E. Griffith (Ed.), Proceedings of the tobacco and health conference. Lexington: University of Kentucky, 1970.

Benowitz, N. L. The use of biologic fluid samples in assessing tobacco smoke consumption. National Institute on Drug Abuse Research Monograph, in press, 1983.

Cohen, M. A., Watson, H., Weisshaut, R., Stott, F., \& SACKNER, M. A. A transducer for noninvasive monitoring of respiration. In F. D. Stott, E. B. Raftery, P. Sleight, \& L. Goulding (Eds.), ISAM 1978: Proceedings of the Second International Symposium on Ambulatory Monitoring. London: Academic Press, 1978.

Comer, A. K., \& Creighton, D. E. The effect of experimental conditions on smoking behaviour. In R. E. Thornton (Ed.), Smoking behaviour-Physiological and psychological influences. London: Churchill Livingstone, 1978.

Creighton, D. E., \& Lewis, P. H. The effect of different cigarettes on human smoking patterns. In R. E. Thornton (Ed.), Smoking behaviour-Physiological and psychological influences. London: Churchill Livingstone, 1978a.

Creighton, D. E., \& Lewis, P. H. The effect of smoking pattern on smoke deliveries. In R. E. Thornton (Ed.), Smoking behaviour-Physiological and psychological influences. London: Churchill Livingstone, $1978 \mathrm{~b}$.

Creighton, D. E., Noble, M. J., \& Wheweld, R. T. Instruments to measure, record and duplicate human smoking patterns. In R. E. Thornton (Ed.), Smoking behoviour-Physiological and psychological influences. London: Churchill Livingstone, 1978.

Epstein, L. H., Ossip, D. J., Hughes, J., \& Wirst, W. Measurement of smoking topography during withdrawal or deprivation. Behavior Therapy, 1982, 12, 507-519.

Erlbacher, J., Gilbert, R., \& Auchincloss, J. H. An impedance pneumograph utilizing an actively regulated constant current source. Journal of Applied Physiology, 1974, 37, 961-967.

Gritz, E. R., Rose, J. E., \& Jarvik, M. E. Regulation of tobacco smoke with paced cigarette presentation. Pharmacology, Biochemistry and Behavior, 1983, 18, 457-462.

Guillerm, R., \& Radziszewski, E. A new method of analyzing the act of smoking. Annales du Tabac, 1975, 1, 101-110.

Guille RM, R., \& RADziszewski, E. Analysis of smoking pattern including intake of carbon monoxide and influence of changes in cigarette design. In R. E. Thornton (Ed.), Smoking behaviour-Physiological and psychological influences. London: Churchill Livingstone, 1978.

Gust, S. W., \& Pickens, R. W. Does nicotine yield affect puff volume? Clinical Pharmacology and Therapeutics, 1982, 32, 418-422.

Henningfield, J. E., \& Griffiths, R. R. A preparation for the experimental analysis of human cigarette smoking behavior. $B e$ havior Research Methods \& Experimentation, 1979, 11, 538-544.

Herning, R. I., Jones, R. T., Bachman, J., \& Mines, A. H. Puff volume increases when low nicotine cigarettes are smoked. British Medical Journal, 1981, 283, 187-193.

Herning, R. I., Jones, R. T., Benowitz, N. L., \& Mines, A. H. How a cigarette is smoked determines nicotine blood levels. Clinical Pharmacology and Therapeutics, 1982, 33, 84-90.

Milledge, J. S., \& SToul, F. D. Inductive plethysmography-A new respiratory transducer. Journal of Physiology, 1977, 267, 18.

NASH, J. C. Compact numerical methods for computers. New York: Wiley-Halsted, 1979.

Rawbone, R. G., Murphy, K., Tate, M. E., \& Kane, S. J. The analysis of smoking parameters, inhalation and absorption of tobacco smoke in studies of human smoking behaviour. In R. E. Thornton (Ed.), Smoking behaviour-Physiological and psychological influences. London: Churchill Livingstone, 1978.

Schievelbein, H. Nicotine, resorption and fate. Pharmacology and Therapeutics, 1982, 18, 233-247.

Shapino, A., \& Cohen, H. D. The use of mercury capillary length gauges for the measurement of the volume of thoracic and diaphragmatic components of human respiration: A theoretical analysis and a practical method. Transactions of the New York Academy of Science, 1965, 27, 634-649.

Sheahon, N. F., Pavia, D., Bateman, J. R. M., Agnew, J. E., \& Clark, S. W. Objective in vivo analysis of antismoking cigarette filters. Thorax, 1981, 36, 213-216.

Stagg, D., Goldman, M., \& DAvis, J. H. Computer aided measurement of breath volume and time components using magnetometers. Journal of Applied Physiology, 1978, 44, 623-631.

Tobin, M. J., \& SACxne r, M. A. Monitoring smoking patterns of low and high tar cigarettes with inductive plethysmography. $A n$ nual Reviews of Respiratory Disease, 1982, 126, 258-264.

Watson, H. The technology of inductive plethysmography. In F. D. Stott, B. Raftery, L. Goulding (Eds.), ISAM 1979: Proceedings of the Third International Symposium on Ambulatory Monitoring. London: Academic Press, 1980.

(Manuscript received August 12, 1983; revision accepted for publication October 17, 1983.) 